\title{
OBITUARY
}

\section{Dr. Muhammad Imran Azeem}

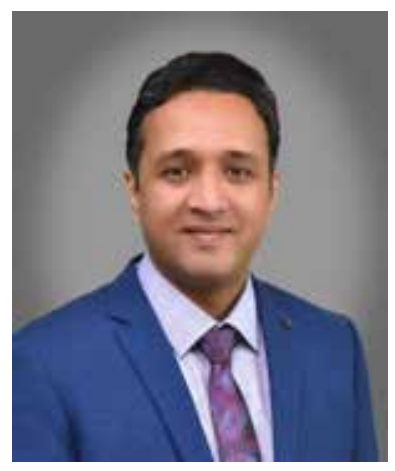

For the Pakistani anesthesia fraternity, 2019 closed with a great deal of pain to boot. Our beloved Dr. Muhammad Imran Azeem left the world on the last day of the year, leaving behind as mourners not just his parents, siblings, wife and children, but a large anesthetic community who had known and loved him.

Imran entered anesthesiology as a resident at Hameed Latif Hospital with the Kaul Associates Lahore in 2005, and this affiliation remained strong till his death. During his career, he worked at Lady Aitchison Hospital Lahore and Lady Willingdon Hospital Lahore as senior registrar and assistant professor respectively. Currently, he was appointed as associate professor of anesthesia at PGMI / Ameer-ud-Din Medical College / LGH Lahore.

For the people who ever came to know him, - friends, students, colleagues and subordinates - Imran was a class apart. His anesthetic prowess, especially when dealing with pediatric patients, was well known amongst those who had worked with him; so were his light-hearted jokes and infectious smile. Many busy evenings at Hameed Latif hospital were enriched by his tall, lanky presence, strolling from OR to OR, lending a hand or cracking a crisp joke whenever, either was needed.

Imran's unexpected death has been untimely by all means. A tragic accident involving a fall from a stair knocked him down with severe head injury on 15 December 2019. He succumbed to his injuries on 31 December 2019, after days on mechanical ventilation. As we bid farewell to the year 2019 and to Dr. Imran Azeem, we pray that the man who helped to put thousands to a gentle sleep, is blessed with a restful eternal sleep himself.

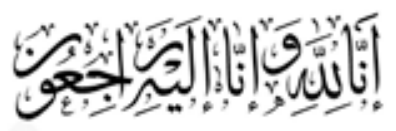

\section{Ashraf Zia \\ Professor of Anesthesiology Jinnah Hospital, Lahore (Pakistan).}




\section{OBITUARY}

\section{Professor Najma Amjad \\ 27 August, 1955 - 9 October, 2019}

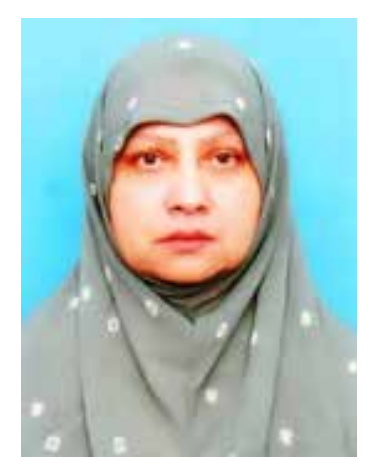

After a long and courageous battle against her disease Prof. Najma Amjad breathed her last on 9th October 2019 at Liaquat National Hospital Karachi. She had been diagnosed as suffering from fourth stage cancer in 2015 and was told by her oncologist that she had only one year to live. Treatment started, but she refused to give up and continued her anesthesia practice, performed Umra, then Hajj and even went to Karbala and Najaf (Iraq) for ziarat.

She did her last anesthesia case on Sunday the 25 th August, 2019 at NMC.

Dr. Najma was an excellent teacher, an examiner at CPSP and a brilliant anesthesiologist.

She graduated from Sind Medical College in 1980, did her MCPS anesthesia in 1983 and FCPS (Anesthesiology) in 1991. She worked as RMO Anesthesia in NICVD from 1983 - 84, passed Federal Public Service Exam and joined JPMC as RMO Anesthesia. In 1991, she was promoted to assistant professor of anesthesia after passing her FCPS.

She joined NICVD in 2001 as associated professor in anesthesia and become HoD in 2007, and was promoted to professor of anesthesia in 2009 till her retirement in August, 2015.

Dr. Najma served as part time faculty of AKUH from 1992 till 2018. She was awarded life time achievement award by PSA in 2017. She had been instrumental in developing pediatric cardiac surgery and anesthesia at NICVD and with her hard work and efforts 12 bedded pediatric cardiac surgical ICU was inaugurated in 2013. She was very kind hearted and sympathetic to her juniors. May God rest her soul in eternal peace and give strength to family to bear this loss. Ameen!

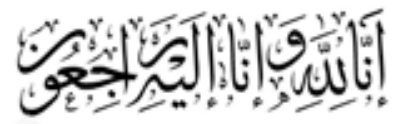

Prof. Amin M. Khuwaja

Head of the Department

Anaesthesia \& ICU

NICVD, Karachi

DOI: https://doi.org/10.35975/apic.v23i4.1182 